\title{
Quinine Levels in Patients with Uncomplicated Falciparum Malaria in the Amazon Region of Brazil
}

José Luiz Fernandes Vieira ${ }^{1}$, Larissa Maria Guimarães Borges ${ }^{2}$, Margareth Tavares Silva Nascimento ${ }^{2}$ and Andreza de L.S. Gomes ${ }^{3}$ ${ }^{1}$ Professor of Toxicology of the Department of Legal Medicine of Federal University of Pará; ${ }^{2}$ Graduate Student (Master's Degree Program in Tropical Disease) of Federal University of Pará; ${ }^{3}$ Undergraduated Student of Federal University of Pará; Belém, PA, Brazil

\begin{abstract}
We examined the plasmatic concentrations of quinine in patients with uncomplicated falciparum malaria in an endemic area of the Amazon region in Brazil in a prospective clinical trial, in which a standard three-day course of oral quinine plus doxycycline was used. We measured the quinine in the plasma samples on days 0 and $3 b y$ high performance liquid chromatography. The mean concentration of quinine was $6.04 \pm 2.21 \mu \mathrm{g} / \mathrm{mL}$ in male patients and $5.98 \pm 1.95 \mu \mathrm{g} / \mathrm{mL}$ in female patients. No significant differences in quinine concentration were observed between these two groups. All samples collected before starting treatment were negative for quinine. This information could help in the development of strategies for the rational use of antimalarial drugs in Brazil. Key-Words: Falciparum malaria, quinine, treatment.
\end{abstract}

The monitoring of quinine blood concentration is an important approach for better understanding the epidemiology of falciparum malaria, especially for a clear distinction between treatment failure, i.e. the absence of resolution of clinical signs after antimalarial treatment associated with inadequate drug concentration, and true resistance to an antimalarial drug [1,2]. Much work has been done to determine how blood quinine concentration profiles correlate with subsequent therapeutic responses in malaria patients; however, the precise therapeutic range of plasma quinine levels remains uncertain, because the pharmacokinetics and the therapeutic response to quinine varies with drug formulation, patient age and immunity, the sensibility of the malaria strain [3,4], the fraction bound to $\alpha 1$-acid-glycoprotein, parasite clearance in the course of the disease and interracial differences in metabolism [5]. However, some authors have stated that continuous concentrations $\geq 6 \mu \mathrm{g} / \mathrm{mL}$ are required to ensure cure $[2,4]$.

There is a lack of knowledge about the plasmatic concentration of quinine in Brazilian falciparum-malaria patients that have been treated with the standard threeday course of oral quinine. We examined the plasmatic concentrations of quinine in patients with uncomplicated falciparum malaria in an endemic area of the Amazon region, in a prospective clinical treatment trial [6].

This study was conducted from January 2006 to January 2007, on 15 adult male and 15 adult female patients with uncomplicated $P$. falciparum malaria admitted to the public Hospital of Tucurui, Amazonas, Brazil. Patients with severe or mixed malaria and pregnancy were excluded. Patients who had taken any antimalarial drugs within the previous 48 hours were also excluded. All patients were monitored for at least 28 days within the malaria

Received on 12 May 2008; revised 10 September 2008.

Address for correspondence: Dr. Jose Luiz Fernandes Vieira. Toxicology Laboratory- Federal University of Pará. Rua Augusto Corrêa 01. Phone: 559132017733. E-mail: jvieira@ufpa.br. Belém, Para, Brazil.

The Brazilian Journal of Infectious Diseases

2008;12(5):353-354 (C) 2008 by The Brazilian Journal of Infectious Diseases and Contexto Publishing. All rights reserved. transmission area. This study was approved by the ethics committee of the Tropical Medicine Center of Para Federal University. Informed consent was obtained from each subject.

After clinical assessment and disease confirmation through microscopic examination of blood smears, all patients were treated with the first line standard threeday oral treatment regimen of quinine (750 mg), twice a day, followed by doxycycline hydrochloride $(100 \mathrm{mg})$, twice a day, for five days and primaquine phosphate (45mg) on the last day [6]. Reappearance of infection was assessed in these patients for at least 28 days.

Venous blood samples were taken for quinine level determination before and on the third day after treatment began. All blood samples were taken before quinine intake. The samples ( $3 \mathrm{~mL}$ ) were collected in heparinized tubes and immediately centrifuged at $1500 \mathrm{x}$ for 15 minutes. The plasma samples were stored at $-20{ }^{\circ} \mathrm{C}$ until analysis. The Student's t test was used to compare the two groups; $\mathrm{P}<$ 0.05 was considered significant.

Quinine was analyzed by high performance liquid chromatography, as described previously [7]. The analytical procedure validated in our laboratory gave within-day and day-to-day coefficients of variation of 6.7 and $8.1 \%$, respectively. Mean extraction recovery of the quinine was $95 \%$. The stability of blank plasma spiked with quinine was 60 days under the conditions described above. Primaquine, doxycycline mefloquine, amodiaquine, acetaminophen and chloroquine do not interfere in the detection of quinine.

All patients recovered following treatment. The mean time for parasite clearance was 70.4 hours, varying from 28 to 108 hours. None of the patients had recrudescent infection, checked until 28 days after treatment.

The mean concentration of quinine in the male plasma samples in the steady state was $6.04 \pm 2.21 \mu \mathrm{g} / \mathrm{mL}$, ranging from 3.08 to $10.04 \mu \mathrm{g} / \mathrm{mL}$; in the female samples it was 5.98 $\pm 1.95 \mu \mathrm{g} / \mathrm{mL}$, ranging from 2.78 to $9.17 \mu \mathrm{g} / \mathrm{mL}$. There were no significant differences between males and females in terms of quinine concentration in the plasma. These levels were similar to what was found in other studies, with plasmatic 
quinine concentration during treatment of falciparum malaria varying from 5.0 to $10.0 \mu \mathrm{g} / \mathrm{mL}$; they are also similar to steady state concentrations of quinine in African and Asian patients with uncomplicated falciparum malaria $[2,8]$.

All samples collected before treatment were negative for quinine and confirmed drug absence. This fact is commonly observed in the Amazon region; it could favor the development of resistance of $P$. falciparum to drugs used in the treatment of this disease.

Quinine concentrations must remain above levels that inhibit parasite multiplication throughout the course of treatment in order to eradicate infection, because there is a significantly higher probability that a resistant strain will emerge if the drug is present at suboptimal concentrations. It is very important to provide an adequate treatment course and to maintain complete adherence to the prescribed drug regimen in order to optimize cure rates and reduce the risks of side effects $[1,3,5]$. This information could be useful for developing strategies for the rational use of antimalarial drugs in Brazil.

\section{References}

1. WHO. World Health Organization- Guidelines for the treatment of malaria. Switzerland. 2006.

2. Pukrittayakamee S., Wanwimolruk S., Stepniewska K., et al. Quinine Pharmacokinetic- Pharmacodynamic Relationships in uncomplicated falciparum malaria. Antimicrob Agents Chemother 2003;47:3458-63.

3. Pukrittayakamee S., Looareesuwan S., Keeratithakul D., et al. A study of the factors affecting the metabolic clearance of quinine in malaria. Eur J Clin Pharmacol 1997;52:487-93.

4. Supanaranond W., Davis T.M., Pukritayakamee S., et al. Disposition of oral quinine in acute falciparum malaria. Eur $\mathrm{J}$ Clin Pharmacol 1991;40:49-52.

5. White N.J. Assessment of the pharmacodynamic properties of antimalarial drugs in vivo. Antimicrob Agents Chemother 1997;41:1413-22.

6. Brasil. Fundação Nacional de Saúde. Manual de Terapêutica da Malária. 2nd. Brasilia, 2001.

7. Dua K.V., Sarin R., Prakash A. Determination of quinine in serum, plasma, red blood cells and whole blood in healthy and Plasmodium falciparum malaria cases by high-performance liquid chromatography. J Chromatogr B Biomed Sci Appl 1993;614:87-93.

8. Flanag K.L., Sharp M.B., Doherty T., Whitty C.J.M. Quinine levels revisited: the value of routine drug level monitoring for those on parenteral therapy. Acta Trop 2006;97:233-7. 